\title{
BMJ Open Risk factors for further sick leave among Japanese workers returning to work after an episode of major depressive disorder: a prospective follow-up study over 1 year
}

Hikaru Hori, ${ }^{1}$ Asuka Katsuki, ${ }^{1}$ Kiyokazu Atake, ${ }^{1}$ Reiji Yoshimura, ${ }^{1}$ Jun Nakamura, ${ }^{2}$ Bernhard T Baune $3,4,5$

To cite: Hori H, Katsuki A, Atake K, et al. Risk factors for further sick leave among Japanese workers returning to work after an episode of major depressive disorder: a prospective follow-up study over 1 year. BMJ Open 2019;9:e029705. doi:10.1136/ bmjopen-2019-029705

- Prepublication history for this paper is available online. To view these files, please visit the journal online (http://dx.doi. org/10.1136/bmjopen-2019029705).

Received 11 February 2019 Revised 21 August 2019

Accepted 23 August 2019
Check for updates

(C) Author(s) (or their employer(s)) 2019. Re-use permitted under CC BY-NC. No commercial re-use. See rights and permissions. Published by BMJ.

For numbered affiliations see end of article.

Correspondence to

Dr Hikaru Hori;

hori-h@med.uoeh-u.ac.jp

\section{ABSTRACT}

Objectives We aimed to investigate the risk factors for further sick leave episodes among Japanese workers returning to work after time off with a major depressive disorder.

Design A prospective study with 1 year of follow-up. Participants We recruited 103 workers who had returned to work after taking sick leave with a major depressive disorder. Adjusted HRs with 95\% Cls were calculated using Cox proportional hazard models to examine the risk of further sick leave.

Results In the adjusted analysis, we show that Social Adaptation Self-evaluation Scale scores (HR 0.95; $\mathrm{p}=0.019$ ), 3-back correct response rate ( $\mathrm{N}$-back test) (HR $0.97 ; p<0.001)$ and benzodiazepine dosage (diazepam equivalent) (HR1.07; $p=0.014$ ) were associated with further episodes of sick leave.

Conclusions Poorer social and cognitive functioning, together with higher diazepam dosages, were associated with an increased likelihood of additional sick leave.

\section{INTRODUCTION}

Major depressive disorder (MDD) is the most common psychiatric illness, affecting some 300 million people worldwide. ${ }^{1}$ The disorder has a significant negative impact on normal functioning and damages work-related outcomes, such as employment status, work productivity and sick leave. ${ }^{2-6}$ In Japan, an increasing number of patients take sick leave because of MDD, and although many could return to work after treatment, they frequently take additional sick leave or resign. ${ }^{7}$ Thus, in addition to improving and stabilising depressive symptoms, ongoing treatment for depression should be to achieve full recovery of social function and continued employment. Factors influencing the ability to work include the severity of a person's depression, social adjustment, and cognitive impairment. ${ }^{89}$
Strengths and limitations of this study

- This is the first prospective follow-up study into the predictors of further episodes of sick leave episodes among Japanese workers.

- The study assessed depressive symptoms, social adaptation and cognitive function to predict the risk of further sick leave.

- We analysed and confirmed several factors associated with further sick leave episodes based on follow-up data over 1 year.

- Unfortunately, the study has a small sample size and the results lack generalisability.

- Despite the broad focus of our assessments, we cannot exclude the possibility that negative emotion bias, social cognition or other unexamined factors affected our results.

There is a lack of prospective research in the English literature investigating factors related to return to work and continuing to work after sick leave for MDD. Various studies have evaluated risk factors for relapse/recurrence of depression, ${ }^{10-18}$ showing that risk increased with factors such as a history of previous episodes, the presence of residual symptoms and decreased psychosocial functioning after the last episode. However, these studies were only performed in healthcare or hospital settings. When considering functioning at work, the requirement for additional sick leave directly causes loss of productivity and can be seen as a significant and measurable outcome. This is unlike issues around reduced functioning at work that may require more input.

We hypothesised that several factors may contribute to the need for additional sick leave. In this study, we assessed depressive symptoms, social adaptation and cognitive 


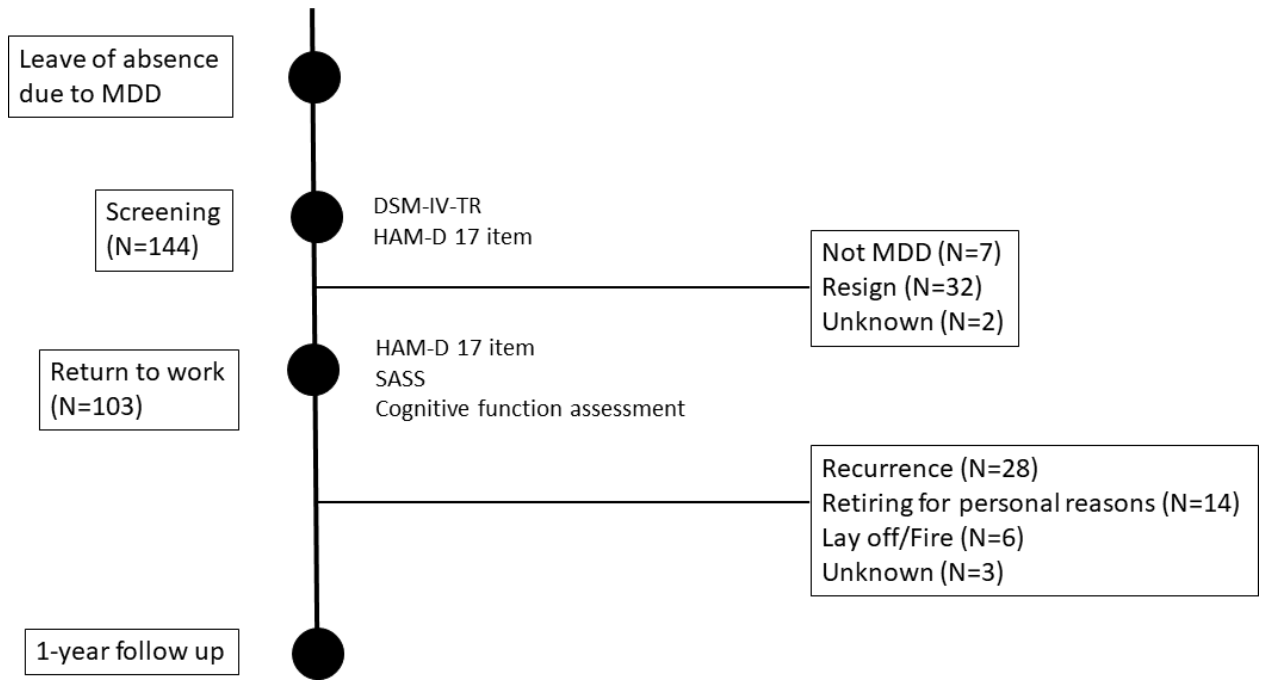

Figure 1 Study design. DSM-IV-TR, Diagnostic and Statistical Manual of Mental Disorders, fourth edition, text revision; HAM-D, Hamilton Depression Rating Scale; MDD, major depressive disorder; SASS, Social Adaptation Self-evaluation Scale.

function in patients when they decided to return to work and examine the factors that affected continued employment over the course of a year.

\section{METHODS}

\section{Study design}

This was a prospective observational follow-up study of a cohort of patients diagnosed with MDD (figure 1). All participants had taken sick leave and showed a desire to return to the same workplace. On deciding to return to work, we conducted three assessments of functioning and performance within 2 weeks of return: depression symptom severity, cognitive functioning and social adaptation. After their returning, participants were followed up prospectively every month by experienced psychiatrists who evaluated their clinical health and working status (figure 2). In total, follow-up lasted 1 year.

We obtained written informed consent from all participants prior to their involvement in the study.

\section{Participants}

We included patients who met the following criteria: (1) attending outpatient services of our university hospital; (2) aged 20-65 years; (3) diagnosed with MDD according to the criteria of the Diagnostic and Statistical Manual of Mental Disorders, fourth edition, text revision (DSM-IV-TR); (4) a Hamilton Depression Rating Scale $(\text { HAM-D })^{19}$ total score $\leq 13$ and (5) currently on sick leave. We excluded patients who had any comorbid central nervous system disorders or severe psychotic symptoms, as well as any patient who met the DSM-IV criteria for alcohol or other substance dependence or for mental retardation. All participants were required to be able to understand the study protocol.

The diagnosis of depression was established based on the structured clinical interview for DSM-IV ${ }^{20}$ and a comprehensive review of the patients' medical records. The criteria used to define a person's ability to return to work were fourfold: (1) the depression had improved to 13 or less on the HAM-D; (2) the worker showed a desire to return to the workplace; (3) an attending psychiatrist determined that return to work was possible and (4) an occupational physician determined that return to work was possible.

\section{Clinical measures}

Depression symptom severity was assessed with the 17-item HAM-D. ${ }^{19}$ 


\begin{tabular}{|c|c|}
\hline Predictor & Total \\
\hline Age, years & $40.6 \pm 10.6$ \\
\hline Sex, male/female & $75 / 28$ \\
\hline Education, years & $13.8 \pm 2.5$ \\
\hline Job changes, number (range) & $1.2 \pm 0.4(0-5)$ \\
\hline Sickness absences, number & $2.4 \pm 1.1$ \\
\hline Admissions, number & $0.69 \pm 0.85$ \\
\hline Marital status, single/married & $42 / 61$ \\
\hline $\begin{array}{l}\text { Daily antidepressant dosage, average, mg/ } \\
\text { day }^{*}\end{array}$ & $126.5 \pm 62.0$ \\
\hline $\begin{array}{l}\text { Daily benzodiazepine dosage, average, mg/ } \\
\text { day† }\end{array}$ & $6.85 \pm 5.22$ \\
\hline HAM-D & $5(0-13)$ \\
\hline SASS & $29.3 \pm 7.2$ \\
\hline WAIS digit span, total & $14.4 \pm 2.8$ \\
\hline \multicolumn{2}{|l|}{ CPT } \\
\hline Correct response rate & $0.85 \pm 0.13(0.45-1.00)$ \\
\hline Correct response reaction time, ms & $537.4(335.7-835.5)$ \\
\hline False response rate & $0.15 \pm 0.10$ \\
\hline False response reaction time, $n=94$ & $601.76 \pm 107.83$ \\
\hline \multicolumn{2}{|l|}{ N-back } \\
\hline 0-back correct response, \% & $94.8 \pm 7.7$ \\
\hline 0-back response time, ms & $619.0 \pm 122.2$ \\
\hline 2-back correct rate, $\%$ & $58.6 \pm 21.3$ \\
\hline 2-back response time, ms & $701.8 \pm 269.2$ \\
\hline 3-back correct rate, \% & $56.0 \pm 17.7$ \\
\hline 3-back response time, $\mathrm{ms}$ & $704.7 \pm 202.9$ \\
\hline \multicolumn{2}{|l|}{ Verbal fluency task } \\
\hline Letter fluency & $40.2 \pm 9.1$ \\
\hline Category fluency & $48.1 \pm 8.7$ \\
\hline
\end{tabular}

*Imipramine equivalent.

$\dagger$ †iazepam equivalent. Data are reported as mean \pm SD or as number (IQR).

CPT, continuous performance task; DSM-IV-TR, Diagnostic and Statistical Manual of Mental Disorders fourth edition text revision; HAM-D, Hamilton Depression Rating Scale; SASS, Social Adaptation Self-evaluation Scale; WAIS, Wechsler Adult Intelligence Scale.

Impaired social functioning, defined as 'an individual's ability to perform and fulfil normal social roles', ${ }^{21}$ was assessed using the Japanese version of the Social Adaptation Self-evaluation Scale (SASS). This 21-item scale was developed by Bosc et al to evaluate social functioning through patient self-report. ${ }^{22}$ The reliability and validity of the Japanese version have been confirmed. ${ }^{23}$ Contained within the SASS are 21 complementary questions relating to the subject's work, relationships with family and friends, intellectual interests, hobbies, satisfaction with one's own performance and ability to manage one's own environment. ${ }^{22}$ Each question is scored from 0 to 3 , and the test is completed in about $10 \mathrm{~min}$. The total score ranges from 0 to 60 , with a higher score indicating better social adaptation.

\section{Tests of cognitive function}

The DSM-IV-TR defines cognitive symptoms of MDD by impairments in decision making, attention and coordination and maintenance of information in working memory. The finding that cognitive deficits occur across multiple domains suggests that, rather than interfering with a specific modality, depression interferes with underlying cognitive faculties and the coordination of cognitive subsystems. Crucial to daily functioning, our cognitive abilities are also pivotal to the severity of several cognitive difficulties associated with depression. Cognitive therapy targets improving cold cognition, with the rationale that this will lead to better performance in hot cognitive tasks, thereby improving everyday function. Moreover, cognitive impairments, by interacting with emotional and social factors, may maintain or exacerbate depression and lead to recurrent episodes. ${ }^{24}{ }^{25}$ In this study, we therefore perform several cognitive assessments.

We assessed forward sequencing and backward sequencing tasks with the digit span task subscale of the Wechsler Adult Intelligence Scale, ${ }^{26}$ which primarily assesses auditory short-term memory. The points of the respective tasks were summed and reported as the raw score.

We evaluated sustained attention and vigilance by the Continuous Performance Task (CPT), using the CPT-Identical Pairs software as described previously. ${ }^{27} \mathrm{On}$ a computer screen, a four-digit number was displayed as a single stimulus, and patients were required to click the mouse as quickly as possible while the stimulus continues (one stimulus is shown for $50 \mathrm{~ms}$, and the interval between stimuli is $950 \mathrm{~ms}$ ). Patients completed 150 trials, 30 of which involve the target. We recorded the correct response rate, correct hit reaction time, false alarm rate and false alarm reaction time.

We used the N-back test ${ }^{28}{ }^{29}$ to assess working memory, which uses working memory task software that requires participants to update their mental set continually while responding to a previously seen stimuli (ie, numbers). ${ }^{28} 29$ The stimulus duration was set to $0.4 \mathrm{~s}$ and the interval between stimuli was set to $1.4 \mathrm{~s}$. We used 0-back, 2-back and 3-back conditions and reported performance as the percentage of correct responses (accuracy, \%) and the reaction times.

Verbal fluency tasks were performed over the letter fluency and category fluency domains. ${ }^{30} 31$ Letter fluency was assessed in three separate trials in which patients were given $60 \mathrm{~s}$ to generate as many as words as possible that begin with the letters $a, k a$ and shi. Category fluency was also assessed in three separate trials in which patients were given $60 \mathrm{~s}$ each to name as many words as possible within the categories animal, sport and job. In both fluency tests, the outcome measure is the total number of words.

To avoid potential confounding factors, we collected the following background information: gender, age, occupation, job rank, number of job switches and number of previous sick leaves at the time of return to work. We also collected information about daily antidepressant and 
Table 2 Cox proportional HR estimates for an unadjusted analysis of predictors of time to additional sick leave

\begin{tabular}{|lllc}
\hline Variable & HR & 95\% Cl & P value \\
\hline Age & 0.98 & 0.96 to 1.01 & 0.221 \\
\hline Sex & 1.89 & 1.07 to 3.32 & 0.028 \\
\hline Number of job changes & 1.10 & 0.92 to 1.32 & 0.302 \\
\hline Number of sickness absences & 1.02 & 0.79 to 1.32 & 0.863 \\
\hline HAM-D & 1.02 & 0.93 to 1.11 & 0.707 \\
\hline SASS & 0.95 & 0.91 to 0.99 & 0.009 \\
\hline Marital status & 0.90 & 0.64 to 1.27 & 0.563 \\
\hline Number of admissions & 0.96 & 0.66 to 1.40 & 0.823 \\
\hline WAIS digit span total & 1.00 & 0.94 to 1.07 & 0.982 \\
\hline CPT correct response rate & 1.47 & 0.18 to 11.87 & 0.719 \\
\hline CPT correct response reaction & 1.00 & 1.00 to 1.00 & 0.695 \\
\hline time & & & \\
\hline CPT false response rate & 1.22 & 0.98 to 1.06 & 0.881 \\
\hline CPT false response reaction & 1.00 & 1.00 to 1.00 & 0.141 \\
\hline time & & & \\
\hline 0-back correct response rate & 1.02 & 0.98 to 1.06 & 0.409 \\
\hline 0-back response time & 1.00 & 1.00 to 1.00 & 0.058 \\
\hline 2-back correct response rate & 1.00 & 0.99 to 1.01 & 0.877 \\
\hline 2-back response time & 1.00 & 1.00 to 1.00 & 0.24 \\
\hline 3-back correct response rate & 0.97 & 0.96 to 0.99 & $<0.001$ \\
\hline 3-back response time & 1.00 & 1.00 to 1.00 & 0.031 \\
\hline Letter fluency & 1.00 & 0.97 to 1.03 & 0.969 \\
\hline Category fluency & 1.00 & 0.97 to 1.03 & 0.877 \\
\hline Imipramine equivalent & 1.00 & 0.99 to 1.00 & 0.436 \\
\hline Diazepam equivalent & 1.04 & 0.99 to 1.10 & 0.083 \\
\hline CPT, contnus pen & & & \\
\hline
\end{tabular}

CPT, continuous performance task; HAM-D, Hamilton Depression Rating Scale; SASS, Social Adaptation Self-evaluation Scale; WAIS Wechsler Adult Intelligence Scale.

benzodiazepine dosages and converted the data into daily imipramine and diazepam equivalents, respectively. ${ }^{32}$

\section{Statistical analysis}

We conducted all statistical tests using IBM SPSS V.22.0 for Windows (IBM, Armonk, New York, USA). We expressed continuous variables with a normal distribution as means $\pm \mathrm{SD}$, and those with skewed distributions as medians with IQRs. We present categorical data as numbers or percentages.

Table 3 Cox proportional HR estimates for the adjusted analysis of predictors of time to additional sick leave

\begin{tabular}{|c|c|c|c|}
\hline Variable & HR & $95 \% \mathrm{Cl}$ & $P$ value \\
\hline SASS & 0.95 & 0.92 to 0.99 & 0.019 \\
\hline $\begin{array}{l}\text { 3-back correct response } \\
\text { rate }\end{array}$ & 0.97 & 0.95 to 0.99 & $<0.001$ \\
\hline Benzodiazepine dosage & 1.07 & 1.01 to 1.12 & 0.014 \\
\hline
\end{tabular}

SASS, Social Adaptation Self-evaluation Scale.
Follow-up assessments were performed 1 year after the subjects' return to work to examine the factors affecting their ability to continue working. Assessments were done by Cox proportional hazard modelling, using the stepwise method to include variables with a $p$ value of $<0.2$. The working duration from the time of return to work to additional sick leave was used as the dependent variable, and we adjusted the analyses for background data (ie, sex, age, occupation, job rank, number of job switches and number of sick leaves), daily imipramine equivalent dose and daily diazepam equivalent dose at the time of return to work.

\section{Patient and public involvement}

Patients and/or public were not involved in the design or planning of the study.

\section{RESULTS}

We enrolled 103 patients diagnosed with MDD (75 males and 28 females) aged 21-65 years. Participants tended to be middle aged, had approximately one job change on average and an average of $2.4 \pm 1.1$ absences due to sickness. The mean HAM-D score at baseline was $6.1 \pm 3.2$, which had decreased from $11.04 \pm 2.07$ at screening, and the mean SASS score was 29.3 \pm 7.2. During the study, 99 patients $(96.1 \%)$ were treated with antidepressants, with the most common being sertraline $(n=24)$, paroxetine $(n=20)$, duloxetine $(n=18)$, milnacipran $(n=14)$, fluvoxamine $(n=10)$, mirtazapine $(n=8)$ and escitalopram $(n=5)$. All baseline demographic data are summarised in table 1 .

\section{Incidence of additional sick leave}

We found that 52 of the 103 participants $(50.5 \%)$ had continued working over the 1-year follow-up period. The reasons for additional sick leave included relapse $(n=28)$, retiring for personal reasons (eg, interpersonal relationships, work environment stress and family relations) $(n=14)$, being laid off or fired $(n=6)$ and unknown factors $(\mathrm{n}=3)$.

\section{Factors of additional sick leave: unadjusted analysis}

Table 2 shows the results of the unadjusted Cox regression analysis. Sex, low SASS score, the 3-back correct response rate and the 3-back response time were each significant as predictors of additional sick leave at the $\mathrm{p}<0.2$ threshold.

\section{Factors affecting additional sick leave: adjusted analysis}

Factors affecting additional sick leave in the Cox adjusted analysis are shown in table 3. Given that we hypothesised that several factors may contribute to additional sick leave, we conducted an adjusted analysis by forward stepwise selection, using all 23 items: age, gender, education, number of job changes, number of sickness absences, number of admissions, marital status, antidepressant dosage, benzodiazepine dosage, HAM-D score, SASS score, CPT result (ie, correct and false response rates and reaction times), N-back result (ie, 0-back, 2-back, 3-back 
correct response rates and times) and verbal fluency task result (letter and category fluency). We observed a strong correlation between letter and category fluencies in the unadjusted analysis and excluded both from the adjusted analysis.

Selection for the Cox proportional hazard model via the stepwise method identified the SASS score, correct response rate in the 3-back task and benzodiazepine dosage as relevant variables at the point of return to work. Notably, the SASS score and 3-back correct response rate were associated with a decreased risk of further absence, whereas the benzodiazepine dosage was associated with an increased risk.

\section{DISCUSSION}

To the best of our knowledge, this is the first study to use prospective data, collected from the time a worker decided to return to work after sick leave for MDD, to predict continued employment. Our focus on workers sets this study apart from other research into MDD, showing that the SASS score, the performance on the 3-back task and the benzodiazepine dosage were associated with continued employment.

Deficits in social skills (ie, lack of smiling, a sad facial expression, avoidance of eye contact, monotonic speech and lack of verbal responses) are demonstrably common among those with low levels of social contact and in depressed patients. ${ }^{33}{ }^{34}$ Such behaviour has been found to result in social rejection by strangers and friends, ${ }^{35}$ and has also been suggested to play an important role in the aetiology and maintenance of depressive symptoms. Thus, social adaptation skills are considered important for adjustment to the workplace and in the aetiology of depressive disorders. It is therefore plausible that higher SASS scores have a preventative effect on a person taking additional sick leave.

The N-back task assesses working memory, with any increase in the size of $\mathrm{N}$ shown to be associated with an increase in the subjective difficulty of a task. Previous research has indicated that the greater task difficulty associated with higher ' $n$ ' values in $n$-back tasks elicited greater activity in the dorsolateral prefrontal cortex, which has a role in working memory. ${ }^{36}$ In this study, we observed no differences for the 0-back or 2-back tasks, but did find a significant difference for the more difficult 3-back task. Critically, therefore, residual cognitive impairment may induce occupational and social dysfunction. ${ }^{89} 378$ This finding has clear relevance to clinical practice.

We also found that the benzodiazepine dosage was related to work continuation. Although benzodiazepines have the potential to decrease cognitive function, we observed no correlation in this study between benzodiazepine dosage when a subject decided to return to work and their cognitive function. While a finding of this type is difficult to interpret, a possibility is that returning to work may have been easier for patients with severe depression, for whom psychiatric symptoms gradually improve when treated with both antidepressants and benzodiazepines. In contrast to our findings, Rizvi $e t a l^{2}$ compared an employed and an unemployed group, and their results showed that the latter had a significantly higher rate of benzodiazepine use. Although it was unclear if this reflected an effect of benzodiazepines alone, it appears that use above certain dose thresholds affects employment and continued employment after return to work.

We noted a $50.5 \%(52 / 103)$ period of continued employment for 1 year after reinstatement in this study, which is low given that we included workers with MDD who were in remission (mean HAM-D-17 score: 6.1 ). The incidence of sick leave and repeated sick leave in Japan is reportedly greater than that in other countries, which may reflect a culture of absenteeism. ${ }^{39}$ Recurrence and personal reasons were the main reasons for additional sick leave. In the future, we plan to investigate whether the rate of continued employment after reinstatement can be increased by cognitive incentives that increase social adaptation.

There are several limitations to this study. First, the sample size was small, and given the relatively large number of explanatory variables, this may have reduced the reliability. Second, this study was conducted in a specific region of Japan, which may preclude the possibility of generalisation to other occupations and regions. Third, although we set minimum standards for reinstatement, the difference in the standards for reinstatement and the amount of overtime at each participating company may have influenced our results. Fourth, we did not record the number of depressive episodes, the duration of the current episode, the severity of previous depressive episodes, the history of treatment resistance or the period of previous sick leave. These factors could have contributed significantly to relapse and the need for additional leave. Fifth, we used forward stepwise selection. It can miss important confounders that have offsetting effects. Sixth, the results of Cox regression analysis suggest that the influence of each factor on the success of return to work rate is small individually, making it difficult to use them to predict successful return to work. Finally, we focused on psychiatric symptoms, social adaptation and neurocognitive functions, but negative emotional biases and social cognitions, as well as other unexamined factors, likely affected the success of reinstatement. Future studies should therefore consider a wider range of variables. $^{40} 41$

In conclusion, our study suggests that social adaptation, working memory function and benzodiazepine dosage are associated with the ability to continue working following a return to work after recovery from MDD. These factors should therefore be considered in clinical settings when reviewing a patient's suitability for return to work.

\section{Author affiliations}

${ }^{1}$ Department of Psychiatry, School of Medicine, University of Occupational and Environmental Health, Kitakyushu, Japan

${ }^{2}$ Kitakyushu Koga Hospital, Kitakyushu, Japan 
${ }^{3}$ Department of Psychiatry and Psychotherapy, University of Münster, Münster, Germany

${ }^{4}$ Department of Psychiatry, Melbourne Medical School, The University of Melbourne, Melbourne, Victoria, Australia

${ }^{5}$ The Florey Institute of Neuroscience and Mental Health, The University of Melbourne, Melbourne, Victoria, Australia

Contributors All authors contributed to and approved the final manuscript. $\mathrm{HH}$ and $\mathrm{JN}$ conceived and designed the experiments; $\mathrm{HH}, \mathrm{AK}, \mathrm{JN}$ and KA performed the experiments; $\mathrm{HH}$ and RY analysed the data; $\mathrm{HH}$ prepared the first manuscript; and $\mathrm{RY}$ and BTB edited the manuscript and revised the manuscript for important intellectual content.

Funding This work was supported by AMED under grant no. JP18dk0307060 and UOEH Research Grant for Promotion of Occupational Health.

Competing interests None declared.

Patient consent for publication Not required

Ethics approval The ethics committee of the University of Occupational and Environmental Health approved the study protocols (no. 270071).

Provenance and peer review Not commissioned; externally peer reviewed.

Data availability statement Data are available on reasonable request. All data relevant to the study are included in the article or uploaded as supplementary information.

Open access This is an open access article distributed in accordance with the Creative Commons Attribution Non Commercial (CC BY-NC 4.0) license, which permits others to distribute, remix, adapt, build upon this work non-commercially, and license their derivative works on different terms, provided the original work is properly cited, appropriate credit is given, any changes made indicated, and the use is non-commercial. See: http://creativecommons.org/licenses/by-nc/4.0/.

\section{REFERENCES}

1. WHO. Depression and other common mental disorders, 2017 Available: http://appswhoint/iris/bistream/10655/254610/1/WHOMSD-MER-20172-engpdf

2. Rizvi SJ, Cyriac A, Grima E, et al. Depression and employment status in primary and tertiary care settings. Can J Psychiatry 2015;60:14-22.

3. Patten SB, Wang JL, Williams JVA, et al. Prospective evaluation of the effect of major depression on working status in a population sample. Can J Psychiatry 2009;54:841-5.

4. Lerner D, Henke RM. What does research tell us about depression, job performance, and work productivity? J Occup Environ Med 2008:50:401-10.

5. Ghassemi GR, Ahmadzadeh GH, Yousefy AR, et al. What are the predictors of work impairment in Iranian patients with depressive disorders? Community Ment Health J 2009;45:453-62.

6. Despiégel N, Danchenko N, François C, et al. The use and performance of productivity scales to evaluate presenteeism in mood disorders. Value Health 2012;15:1148-61.

7. Endo M, Haruyama Y, Muto T, et al. Recurrence of sickness absence due to depression after returning to work at a Japanese IT company. Ind Health 2013;51:165-71.

8. Fried $\mathrm{El}$, Nesse RM. The impact of individual depressive symptoms on impairment of psychosocial functioning. PLoS One 2014;9:e90311.

9. Clark M, DiBenedetti D, Perez V. Cognitive dysfunction and work productivity in major depressive disorder. Expert Rev Pharmacoecon Outcomes Res 2016;16:455-63.

10. Winokur G, Coryell W, Keller M, et al. A prospective follow-up of patients with bipolar and primary unipolar affective disorder. Arch Gen Psychiatry 1993;50:457-65.

11. Pintor L, Torres X, Navarro V, et al. Is the type of remission after a major depressive episode an important risk factor to relapses in a 4-year follow up? J Affect Disord 2004;82:291-6.

12. Mueller TI, Leon AC, Keller MB, et al. Recurrence after recovery from major depressive disorder during 15 years of observational follow-up. Am J Psychiatry 1999;156:1000-6.

13. Maj M, Veltro F, Pirozzi R, et al. Pattern of recurrence of illness after recovery from an episode of major depression: a prospective study. Am J Psychiatry 1992;149:795-800.

14. Keller MB, Lavori PW, Lewis CE, et al. Predictors of relapse in major depressive disorder. JAMA 1983;250:3299-304.

15. Judd LL, Akiskal HS, Maser JD, et al. Major depressive disorder: a prospective study of residual subthreshold depressive symptoms as predictor of rapid relapse. J Affect Disord 1998;50:97-108.
16. Gopinath S, Katon WJ, Russo JE, et al. Clinical factors associated with relapse in primary care patients with chronic or recurrent depression. J Affect Disord 2007;101:57-63.

17. Gonzales LR, Lewinsohn PM, Clarke GN. Longitudinal follow-up of unipolar depressives: an investigation of predictors of relapse. $J$ Consult Clin Psychol 1985;53:461-9.

18. Conradi HJ, de Jonge P, Ormel J. Prediction of the three-year course of recurrent depression in primary care patients: different risk factors for different outcomes. J Affect Disord 2008;105:267-71.

19. Hamilton M. Development of a rating scale for primary depressive illness. Br J Soc Clin Psychol 1967;6:278-96.

20. First MB, Gibbon M, Spitzer RL, et al. Users Guide for the Structured Cllinical Interview for DSM-IV Axix Disorders-Research Versopm(SCID-, version 2.0, February 1996 Final Version). New York: Biometric Research Department, 1996.

21. Hirschfeld RM, Montgomery SA, Keller MB, et al. Social functioning in depression: a review. J Clin Psychiatry 2000;61:268-75.

22. Bosc M, Dubini A, Polin V. Development and validation of a social functioning scale, the social adaptation Self-evaluation scale. Eur Neuropsychopharmacol 1997;7(Suppl 1):S57-70.

23. Ueda N, Suda A, Nakagawa M, et al. Reliability, validity and clinical utility of a Japanese version of the social adaptation Self-evaluation scale as calibrated using the Beck depression inventory. Psychiatry Clin Neurosci 2011;65:624-9.

24. Weightman MJ, Air TM, Baune BT. A review of the role of social cognition in major depressive disorder. Front Psychiatry 2014;5.

25. Raes F, Williams JMG, Hermans D. Reducing cognitive vulnerability to depression: a preliminary investigation of MEmory Specificity Training (MEST) in inpatients with depressive symptomatology. $J$ Behav Ther Exp Psychiatry 2009;40:24-38.

26. Wechsler D. Wechsler adult intelligence scale. 3rd edn. San Antonio: The Psychological Corporation, 1997.

27. Cornblatt BA, Risch NJ, Faris G, et al. The Continuous Performance Test, Identical Pairs version (CPT-IP): I. New findings about sustained attention in normal families. Psychiatry Res 1988;26:223-38.

28. Callicott JH, Egan MF, Mattay VS, et al. Abnormal fMRI response of the dorsolateral prefrontal cortex in cognitively intact siblings of patients with schizophrenia. Am J Psychiatry 2003;160:709-19.

29. Callicott JH, Bertolino A, Mattay VS, et al. Physiological dysfunction of the dorsolateral prefrontal cortex in schizophrenia revisited. Cereb Cortex 2000;10:1078-92.

30. Nakano $\mathrm{Y}$, Baba $\mathrm{H}$, Maeshima $\mathrm{H}$, et al. Executive dysfunction in medicated, remitted state of major depression. J Affect Disord 2008;111:46-51.

31. Lezak MD, Howieson DB, Loring David W, et al. Neuropsychological assessment. 4th edn. New York, NY, US: Oxford University Press, 2004.

32. Inada T, Inagaki A. Psychotropic dose equivalence in Japan. Psychiatry Clin Neurosci 2015;69:440-7.

33. Segrin C, Abramson LY. Negative reactions to depressive behaviors: a communication theories analysis. J Abnorm Psychol 1994;103:655-68.

34. Cohen S, Sherrod DR, Clark MS. Social skills and the stress-protective role of social support. J Pers Soc Psychol 1986;50:963-73.

35. Tse WS, Bond AJ. Consequences of displaying abnormal social behaviour: avoidance and reduction of social reinforcement. J Affect Disord 2003;75:49-58.

36. Braver TS, Cohen JD, Nystrom LE, et al. A parametric study of prefrontal cortex involvement in human working memory. Neuroimage 1997;5:49-62.

37. Mclntyre RS, Lee Y. Cognition in major depressive disorder: a 'Systemically Important Functional Index' (SIFI). Curr Opin Psychiatry 2016;29:48-55.

38. Baune BT, Miller R, McAfoose J, et al. The role of cognitive impairment in general functioning in major depression. Psychiatry Res 2010;176:183-9.

39. Evans-Lacko S, Knapp M. Global patterns of workplace productivity for people with depression: absenteeism and presenteeism costs across eight diverse countries. Soc Psychiatry Psychiatr Epidemiol 2016:51:1525-37.

40. Knight MJ, Baune BT. Psychosocial dysfunction in major depressive Disorder-Rationale, design, and characteristics of the cognitive and emotional recovery training program for depression (CERT-D). Front Psychiatry 2017;8

41. Baune BT, Air T. Clinical, functional, and biological correlates of cognitive dimensions in major depressive disorder - rationale, design, and characteristics of the cognitive function and mood study (CoFaM-Study). Front Psychiatry 2016;7. 